\title{
Capsule Commentary on Jacobs et al., Development and Validation of the Spanish-Numeracy Understanding in Medicine Instrument
}

\author{
Jeffrey L. Jackson, MD MPH \\ Zablocki VAMC, Milwaukee, WI, USA. \\ J Gen Intern Med 31(11): 1359 \\ DOI: $10.1007 / \mathrm{s} 11606-016-3842-8$ \\ () Society of General Internal Medicine 2016
}

$\mathrm{L}$ iteracy and numeracy are emerging as important domains in the management of patients. Low literacy is associated with poorer health outcomes. ${ }^{1}$ Numeracy is considered a subdomain of literacy, and there is an emerging literature showing the adverse health consequences of poor numeracy. Limited English proficiency patients have problems with numeracy, particularly when tests are administered in English rather than their native language. In this study, the authors report on the validity and reliability of a Spanish translation of their Numeracy Understanding in Medicine instrument. ${ }^{2}$

Jacobs et al. tested this Spanish language version in 232 patients. Their study population had substantial problems with literacy, with nearly half ( $41 \%$ ) of subjects having inadequate or marginal health literacy. Starting with a bank of 96 items, they found that a six-question version of the numeracy questionnaire had the best test characteristics. This rigorous study provides evidence that the instrument is valid and reliable. For the average clinician, this paper will be difficult to read, focusing on tests of reliability and validity. What is missing from this paper is a practical guide for clinicians on how to use this instrument. There is no discussion of how to score the instrument or what cut points clinicians should use in determining if their Spanish-speaking patients are struggling with numeracy. This is particularly disappointing because the

authors' paper on testing the validity and reliability of the English version has these clearly explained. ${ }^{3}$ In personal communication with Dr. Jacobs, she suggests that scores less than 2 would be evidence of low numeracy, scores of 3-4, average numeracy, and scores greater than 5 , high numeracy. While measuring literacy is important, the next step needs to be testing interventions to improve the quality of communication among low-numeracy (and literacy) populations. The correlation between low literacy/numeracy and disparity suggests an avenue for reducing health disparities, but this hope needs to be explored with rigorous trials to make sure the association is causal and not a confounded relationship.

Corresponding Author: Jeffrey L. Jackson, MD MPH; Zablocki VAMC, Milwaukee, WI, USA (e-mail: jjackson@mcw.edu).

\section{Compliance with Ethical Standards:}

Conflicts of Interest: The author has no conflicts of interest with this article.

\section{REFERENCES}

1. Berkman ND, Sheridan SL, Donahue KE, Halpern DJ, Crotty K. Low health literacy and health outcomes: an updated systematic review. Ann Intern Med. 2011;155:97-107.

2. Jacobs EA, Walker CM, Miller T, Fletcher KA, Ganschow PG, Imbert D, O'Connel M, Neuner JA, Schapira MM. Development and Validation of the Spanish-Numeracy Understanding in Medicine Instrument. J Gen Intern Med. doi:10.1007/s11606-016-3759-2

3. Schapira MM, Walker CM, Miller T, et al. Development and validation of the numeracy understanding in Medicine Instrument short form. J Health Commun. 2014;19(Suppl 2):240-53. 